\title{
Sometimes patience pays off: When amputation is the alternative
}

\author{
Iraklis Delikonstantinou, Polyxeni Zapantioti, Andreas Gravvanis, Dimosthenis Tsoutsos \\ Department of Plastic Surgery, Microsurgery and Burn Centre; "J. loannovich», General Hospital of Athens "G. Gennimatas», \\ Athens, Greece
}

Received: May 26, 2016

Accepted: July 4, 2016

Online Published: July 12, 2016

DOI: $10.5430 /$ css.v2n3p31

URL: http://dx.doi.org/10.5430/css.v2n3p31

\begin{abstract}
Extended lower extremities defects due to systemic diseases can lead to amputation. This study aims to illustrate the successful treatment of two patients with chronic and therapy-resistant soft tissue defects of the lower leg, which healed with the use of gamma-irradiated human skin allograft (Gammagraft ${ }^{\mathrm{TM}}$, Promethean LifeSciences Inc, Pittsbourgh, PA/USA) and artificial dermis (Integra ${ }^{\mathrm{TM}}$, Integra LifeSciences Corporation, Plainsboro, NJ/USA) respectively. Both patients presented at admission with extended lower leg necrotic ulcers and both had a positive history of vasculopathy. The patient A was a 42 years old, male, with Scleromyxedema (SM) and the patient B was a 52 years old, female, diabetic and thrombophilic, which also suffered from Systemic Lupus Erythematosus (SLE). Serial wound debridements, amputation of single toes and skin grafting, were paired with modern reconstructive tools, like hydrosurgery system (Versajet ${ }^{\triangleright}$, Smith \& Nephew, London/UK), Vacuum Assisted Closure system (VAC $\AA$, KCI, San Antonio, Tx/USA) and tissue engineered products: Gammagraft ${ }^{\mathrm{TM}}$ on patient A and Integra ${ }^{\mathrm{TM}}$ on patient B. The follow up revealed a long-term durable coverage of the defects. While there is no evidence to support a gold standard for extended chronic lower extremities defects of such origin, whose other alternative seems to be amputation, we believe that patience combined with the use of different reconstructive methods can add another valuable tool in our armamentarium and should considered as a valid reconstructive option.
\end{abstract}

Key Words: Lower extremity soft tissue defect, Biotechnology, Scleromyxedema, Lupus erythematosus

\section{INTRODUCTION}

Wound healing represents a complex process that involves several events. In chronic, non-healing wounds, this process is completely disrupted because of various general or local causes. Systemic diseases with an angiopathic profile such as Systemic Lupus Erythematosus (SLE) and Scleromyxedema (SM) can deteriorate the normal cascade of wound healing process resulting in chronic and therapy-resistant soft tissue defects that impair patient's quality of life. ${ }^{[1]}$

SLE is an autoimmune disease in which organs, tissues, and cells undergo damage mediated by tissue-binding autoanti- bodies and immune complexes. Vascular damage in SLE occurs through vasculitis, Raynaud phenomenon, premature atherosclerosis, hypercoagulability due to antiphospholipid antibodies and high homocystine levels. ${ }^{[2]}$ Vascular disease and thromboembolic episodes consequences are necrotic ulcers and tissue defects.

On the other hand, SM is a generalized and sclerodermoid form of lichen myxedematosus. It is a rare cutaneous pathology of unknown aetiology with systemic manifestations that may lead to significant morbidity and mortality. ${ }^{[3]}$ The etiology of non-healing lower extremity ulcers in these patients

\footnotetext{
*Correspondence: Iraklis Delikonstantinou; Email: idelikonstantinou@gmail.com; Address: 11 Court Road Chelmsford, Essex, CM1 7EW, United Kingdom.
}

Published by Sciedu Press 
is often multifactorial. ${ }^{[4]}$ Raynaud's phenomenon, vasculitis, liveloid vasculopathy, a hypercoagulable and prothrombotic state all contributing to chronic non-healing leg ulcers in such diseases. ${ }^{[1]}$

Additionally, the concomitant immunosuppressive medical therapy along with other comorbidities of diseases' spectrum complicates the wound healing process leading to chronicity of the problem. In this particular group of patients, coverage provided by local or regional flaps is not available, while simultaneously, are poor candidates for lengthy operations and microvascular free transfer reconstruction.

This study aims to illustrate that the introduction of technologies such as Vacuum Assisted Closure (VAC) and Versajet hydro-surgery system along with tissue-engineering products such as artificial dermis and gamma-irradiated human cadaveric skin allograft could enhance our therapeutic approach by offering a valid alternative of treatment of chronic leg ulcers.

\section{Cases presentation}

Two patients were included in this study.

A multidisciplinary approach was adopted for both patients including a rheumatologist, an internist, a vascular surgeon and physiotherapists. A written informed consent was discussed and signed by the patients prior to any therapeutic intervention or photograph taking.

Their records, charts and clinical course were reviewed.

At admission, they equally presented, with extended necrotic eschars of both their lower extremities and concomitant digital gangrene while both had experienced previous treatments with serial debridement and various dressings. The patients were smokers and both had a positive history of vascular disease. The ulcers were painful and none of the patients was ambulatory.

Both our patients underwent blood exams preoperatively while wound culture sampling orientated our chemoprophylaxis regimen. Punch biopsies were also taken from both patients ulcers in order to exclude a possible malignant transformation.

Patient A was a forty-two years old male smoker, with SM and presence of non-healing leg ulcers for 12 months. On examination, he presented with large soft tissue defects of both legs and feet while the peripheral pulses were not palpable. Doppler exam of the extremities demonstrated an occlusive flow pattern of tibial vessels. This was confirmed by an angiogram, which revealed stenosis of both posterior tibial arteries and right anterior tibial artery. A multi stage approach was decided. The patient underwent surgi- cal debridement and amputation of necrotic toes, using the conventional method (scalpel) and the hydro-surgery system (Versajet), under regional anaesthesia (see Figure 1). Versajet is based on Fluidjet technology that uses the Venturi effect in order to debride selectively eschars of necrotic tissue. At this stage the defects were not skin grafted and the VAC system was used for a period of 12 days. VAC therapy applies topical negative pressure to promote the formation of granulation tissue of difficult-to-heal chronic wounds by reducing edema and thus improving blood flow to a wound site. We applied a mean pressure of $60 \mathrm{mmHg}$ (range 50-70 $\mathrm{mmHg}$ ) intermittently. VAC dressings were changed every three to four days. Gammagraft sheets were then applied over the defects. Gammagraft is a bioengineered tissue of irradiated cadaveric human skin. Dressings consisting of paraffin and antiseptic impregnated gauzes, were changed on a daily basis, following saline irrigation of the wounds.

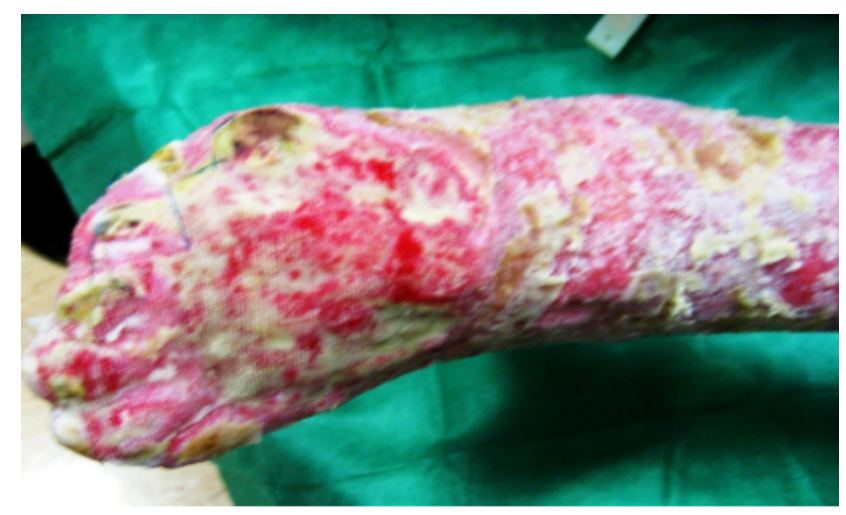

Figure 1. Patient A after initial debridement and toes amputation, prior to VAC therapy

Note the extensive skin defect and the slough covering his right lower extremity and foot

After a period of 14 days, Gammagraft sheets were removed, and the remaining defects were split thickness skin grafted.

Normal wound healing of the skin grafts was observed. After physiotherapy, the patient was discharged the eighth postoperative day (see Figure 2A and 2B). The total hospital stay was 40 days.

Patient B was a fifty-two years old female smoker, with insulin-dependent diabetes, antiphospholipid syndrome and systematic lupus erythematosus with an 8 month history of bilateral lower leg ulcers.

She was suffering from extended necrotic ulcers of both lower extremities with gangrenous alterations of both first toes and left small finger. Peripheral pulses of dorsalis pedis and posterior tibial arteries were weak on palpation and Colour Doppler investigation showed a monophasic flow 
pattern. After completition of the preoperative assessment she had surgical debridement and amputation of necrotic toes, under regional anaesthesia (see Figure 3A and 3B).
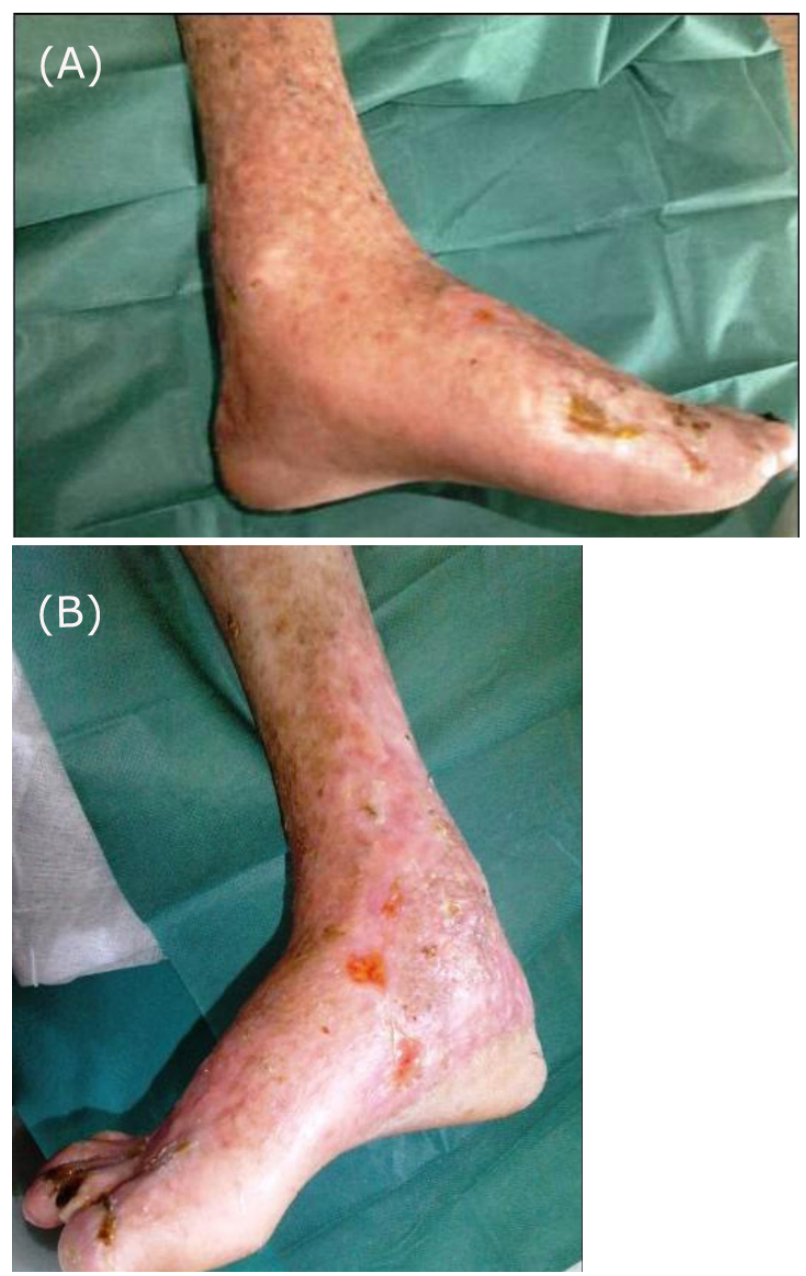

Figure 2. A, B: Patient A, early postoperative result shows satisfactory coverage of the extremities

A VAC dressing is then applied for 10 days. A mean pressure of $60 \mathrm{mmHg}$ was applied intermittently, taking count the insufficient arterial supply of her legs.

During the second surgical stage, the defects were covered with Integra artificial dermis. Integra is an acellular dermal substitute composed of (bovine) Type I collagen and chondroitin-6-sulfate on a silicone backing. More than $80 \%$ take of Integra was recorded (see Figure 4A), and the patient was successively split-thickness skin grafted three weeks post-Integra application. Although grafting was successful (see Figure 4B), and physiotherapy started gently the fourth post-operative day, the patient had to remain admitted under the rheumatology team, in order to optimise her general medical status. This resulted in a prolonged hospital stay of 72 days.

Published by Sciedu Press
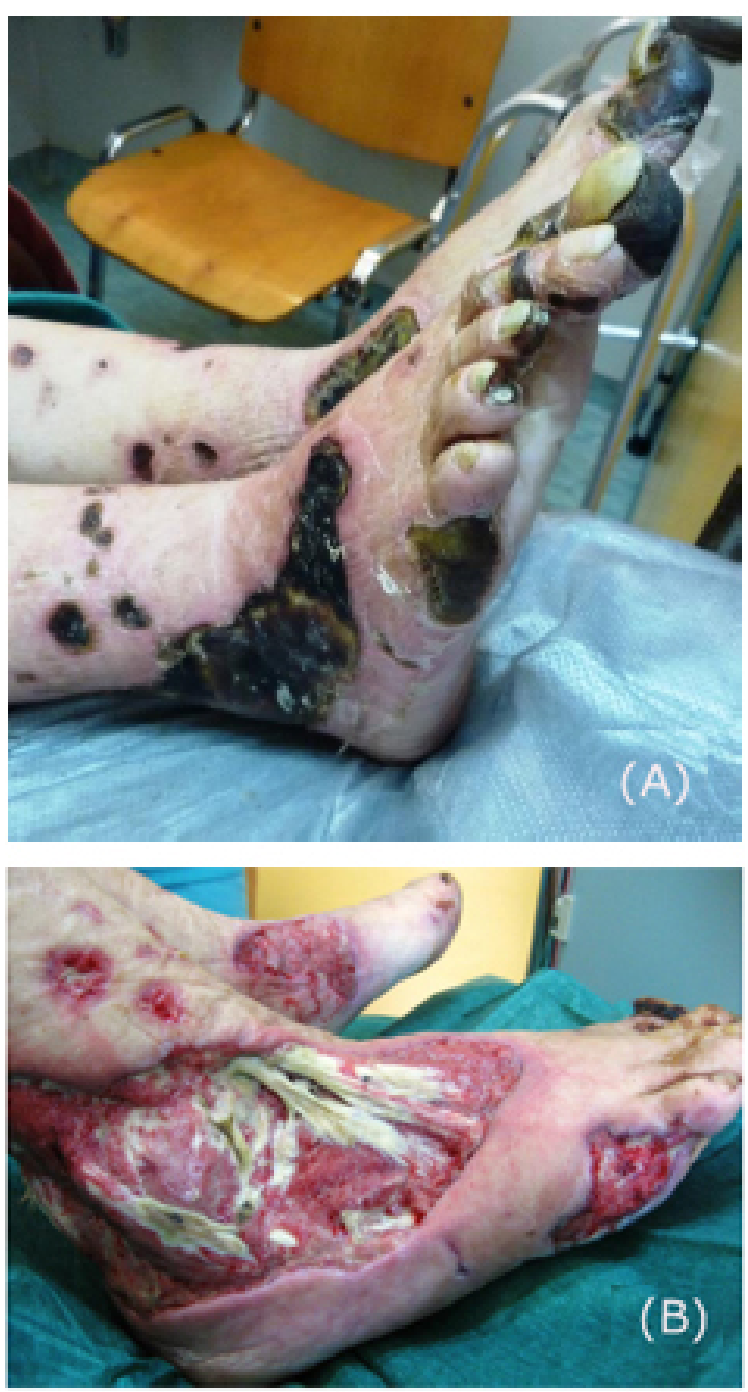

Figure 3. Patient B at presentation and post debridement (A) Patient $B$ at presentation, with extensive necrotic eschars; (B) Patient B after debridement and during the VAC therapy. Extensor tendons of right foot are completely exposed

During the management of these patients our aim was to transform their chronic wounds to acute by correcting their medical abnormalities, controlling infection, restoring adequate blood flow and most importantly debriding them aggressively.

Following the first surgical stage of debridement, patients were presented with exposed tendons. VAC therapy was applied, in order to promote granulation, to resolve leg edema and decrease the bacterial population.

When granulation was successfully occurred, both patients were introduced to the second surgical stage where irradiated human skin allograft (patient A) and artificial dermis (patient B), were respectively applied.

Both patients were ambulatory at discharge and presented 
a stable and durable soft tissue coverage of their defects at their follow-up appointments.
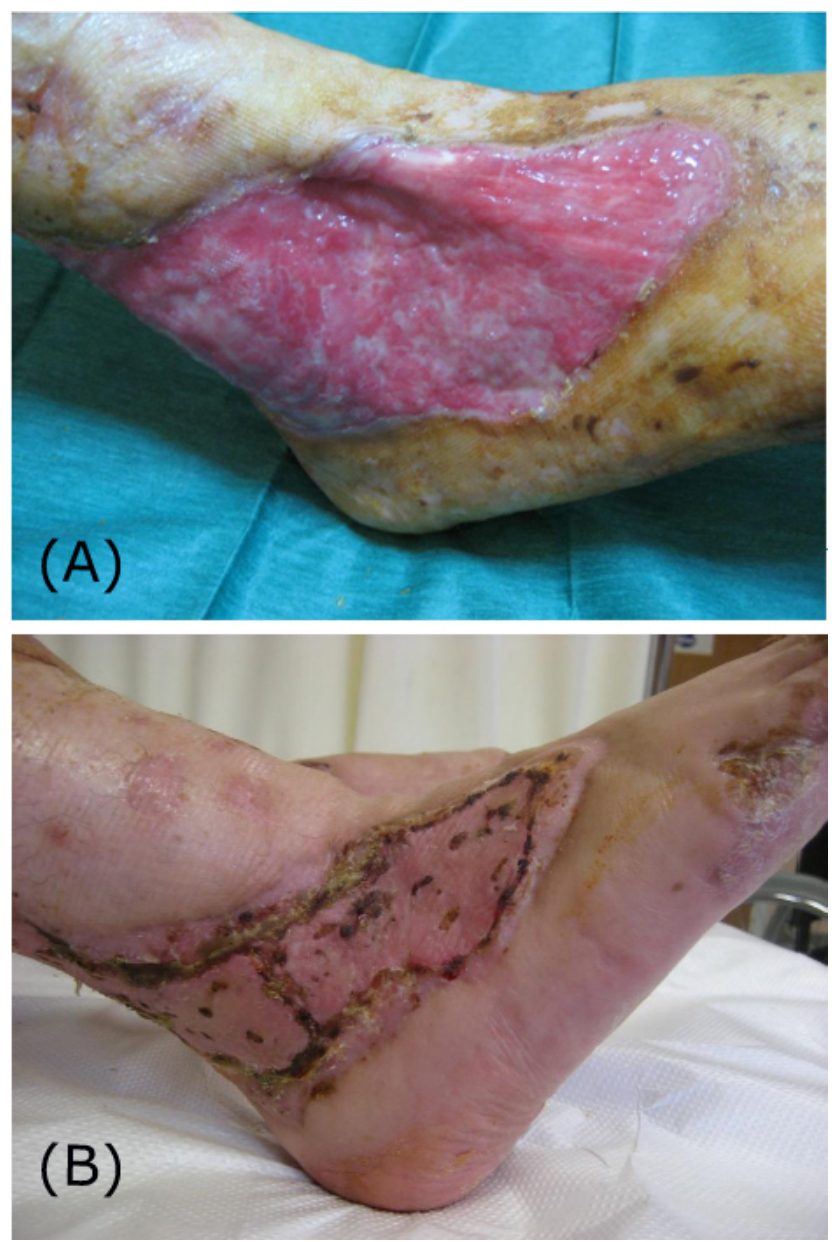

Figure 4. Patient $B$ after the first stage and the second stage of reconstruction with artificial dermis

(A) Patient B after use of VAC and Integra artificial dermis.

Granulation tissue is now covering the extensor compartment of the foot;

(B) Patient B, early result after skin grafting with good coverage of the defect

\section{Discussion}

Lower extremity ulcers are considerably more common in patients with connective tissue disorders as well as autoimmune diseases than in the general population. This category of patients is complicated with poor wound healing and chronic, therapy-resistant leg ulcers. ${ }^{[1]}$ The pathology is multifactorial, often characterized by several processes acting in synergy. The spectrum includes vasculitis, Raynaud vasospasm, or prothrombotic states and vasculopathy that precipitate ulceration and impair wound healing. ${ }^{[1]}$

This cases report aims to highlight the management of leg ulcers in patients with significant comorbidities which may complicate and eventually delay wound healing.
Patient A suffered from SM where skin is characteristically indurated and popular. The exact prevalence of SM is unknown. However, it is a rare entity of unknown etiology. ${ }^{[5,6]}$ Moreover, the patient was a smoker and the angiographyconfirmed peripheral vascular disease aggravated his leg ulcers.

On the other hand, patient B suffered from SLE complicated by antiphospholipid antibodies syndrome and diabetes mellitus. Bibliography states that leg ulcerations can occur in SLE patients with antiphospholipid antibodies ${ }^{[7]}$ and interestingly, patients with antiphospholipid syndrome are prone to thromboembolic episodes, which can lead to limb amputation. ${ }^{[8]}$ This patient was also smoker and diabetic, conditions that also lead to impaired wound healing.

Subsequently, in both our patients, wound healing process was pathologically interrupted and both suffered from a chronic and relevant tissue loss. The wounds were covered by necrotic tissue or fibrin slough with an abundant and/or malodorous exudate and other contaminants.

When we face wounds at this stage, which amputation maybe the alternative, the surgical debridement along with infection control and amelioration of blood inflow are mandatory to promote the healing process.

Firstly, wound-bed preparation can be achieved with several methods: autolytic, enzymatic, biological, mechanical and surgical. In our cases, classic surgical debridement of gangrenous toes was paired with Versajet Hydrosurgery System. This system is a new technology that simultaneously cuts and aspirates soft tissue. Current bibliographic data describes Versajet as a valuable procedure in ulcer debridement. When is properly used, the debridement can be selective, quicker, with less bleeding and pain, than conventional methods. It also reduces the bacterial load and enhances the following split thickness skin graft take. ${ }^{[9-11]}$

After debridement, both patients resulted with exposed tendons. In order to accelerate the formation of granulation tissue and manage the bacterial colonization, a VAC system was applied postoperatively in both patients.

VAC therapy has been used successfully, in variable cases of soft tissue deficits, either acute or chronic to induce faster wound healing. VAC dressing creates a vacuum-induced negative pressure to a specific wound area resulting in an accelerated formation of granulation tissue in the wound bed. Furthermore, by reducing the interstitial edema enhances oxygen delivery to the wound tissue. VAC device is a particularly versatile tool having a wide range of clinical applications, including chronic untreatable leg ulcers. ${ }^{[12]}$ 
We have used both Versajet and VAC aiming to create an ideal wound bed necessary for the next surgical stage. According to our knowledge, there are not many reports, where the two therapies are combined. In both studies, the authors' scope was to successfully debride the wound and to create a healthy layer of granulation tissue over its surface. ${ }^{[13,14]}$

The next step was to provide a durable as well as stable coverage of the defects. This was achieved by employing Gammagraft irradiated human skin and Integra artificial dermis respectively.

A gamma-irradiated cadaveric allograft, Gammagraft contains both epidermal and dermal components. It is primarily designed a temporary biologic dressing requiring multiple applications, but can be also left upon the wound until complete epithelialisation. It has been reported that decreases pain at the site of application while acting as a protective dressing. Furthermore, decreases the amount of fluid and protein loss through the wound and decreases the bacterial load. ${ }^{[15]}$ Gammagraft has been used in burn treatment and for both acute and chronic wounds of partial and full thickness skin loss. ${ }^{[15,16]}$

Integra is a bilaminar membrane system consisting of bovine tendon collagen and shark glycosaminoglycan covered by a temporary epidermal substitute made of silicone. Although initially developed for burn injury coverage, its properties make it a useful tool for a variety of situations including chronic and/or infected leg ulcers. ${ }^{[17]}$ Among its principal disadvantages are the high economic cost and the two-stage operation.

The management of chronic and therapy resistant leg skin ulcers represents a challenge for the reconstructive surgeon as most frequently these patients suffer from systemic comorbidities, which complicate the situation. Bibliography suggests several tissue-engineered products to cope with this problem like the use of allogeneic cultured dermal substitute, ${ }^{[18,19]}$ cultured epithelial autografts, ${ }^{[20]}$ growth factors $^{[21,22]}$ or autologous skin grafting. ${ }^{[23]}$ Most of these reports are cases presentations reflecting the fact that there is no evidence to support a gold standard method of treatment for extended chronic lower extremities defects of such origin.

\section{REFERENCES}

[1] Shanmugam VK, Steen VD, Cupps TR. Lower extremity ulcers in connective tissue disease. Isr Med Assoc J. 2008; 10(7): 534-6. PMid: 18751636

[2] Petri M. Thrombosis and SLE. Scand J Rheumatol. 1996; 25: 191-
Reviewing with criticism our practice; the drawbacks of this kind of management are the high economic cost, the multiple operations and the long hospital admission.

The prolonged hospital stay can be explained by the multistage therapeutic plan and also by the fact that both patients were referred from district county hospitals where the application of such therapies including rehabilitation was not possible. Moreover, for patient B, where the hospitalisation is significantly protracted; she had to remain inpatient in order to optimise her medical and rheumatologic conditions before discharge.

This study reports the successful management of two only patients with chronic leg ulcers and significant medical background of connective tissue pathologies.

A series of similar patients with a comparison of the techniques applied in this study with more traditional techniques of debridement and straightforward skin grafting, would be indispensable in order to extract a more substantial conclusion.

Nevertheless, tissue-engineered products, despite their high cost, may be cost-effective if their use is restricted to ulcers that are unresponsive to healing.

\section{Conclusions}

The durable and stable coverage of lower extremity ulcers in patients with a systemic disease complicated by vasculopathy and thromboembolic episodes represents a formidable challenge. Although this study presents the successful management of two only cases of such ulcers, we believe that the use of bioengineered products after an aggressive but selective debridement could enhance their final management and prevent amputations.

Among the disadvantages of this practice are the high economic cost, the multistage surgical approach and the long period of hospitalization. Thus, we suggest a similar management only in selected cases, where extended chronic leg ulcers are complicated by systemic comorbidities and are resistant to conventional methods of wound healing.

\section{CONFLICTS OF INTEREST Disclosure}

The authors declare they have no conflicts of interest.
3. PMid: 8792794. http://dx.doi.org/10.3109/030097496 09069986

[3] Georgakis CDC, Falasca G, Georgakis A, et al. Scleromyxedema. Clin Dermatol. 2006; 24: 493-7. PMid: 17113967. http://dx.doi .org/10.1016/j.clindermatol.2006.07.011 
[4] Hafner J, Schneider E, Burg G, et al. Management of leg ulcers in patients with rheumatoid arthritis or systemic sclerosis: the importance of concomitant arterial and venous disease. J Vasc Surg. 2001; 32(2): 322-9. PMid: 10917993. http://dx.doi.org/10.1067/m va. 2000.106942

[5] Rongioletti F. Lichen myxedematosus (papular mucinosis): new concepts and perspectives for an old disease. Semin Cutan Med Surg. 2006; 25(2): 100-4. PMid: 16908401. http://dx.doi.org/10. 1016/j.sder.2006.04.001

[6] Boin F, Hummers LK. Scleroderma-like fibrosing disorders: Rheum Dis Clin North Am. 2008; 34(1): 199-220. PMid: 18329541. http://dx.doi.org/10.1016/j.rdc.2007.11.001

[7] Reddy V, Dziadzio M, Hamdulay S, et al. Lupus and leg ulcersa diagnostic quandary. Clin Rheumatol. 2007; 26(7): 1173-5. PMid: 16633706. http://dx.doi.org/10.1007/s10067-006 -0306-2

[8] Asherson RA, Cervera R, Klumb E, et al. Amputation of digits or limbs in patients with antiphospholipid syndrome. Semin Arthritis Rheum. 2008; 38(2): 124-31. PMid: 18206213. http: //dx.doi.org/10.1016/j.semarthrit.2007.10.013

[9] Mosti G, Iabichella ML, Picerni P, et al. The debridement of hard to heal leg ulcers by means of a new device based on Fluidjet technology. Int Wound J. 2005; 2(4): 307-14. PMid: 16618317 http://dx.doi.org/10.1111/j.1742-4801.2005.00147.x

[10] Caputo WJ, Beggs DJ, DeFede JL, et al. A prospective randomised controlled clinical trial comparing hydrosurgery debridement with conventional surgical debridement in lower extremity ulcers. Int Wound J. 2008; 5(2): 288-94. PMid: 18494634. http://dx.doi.o $\mathrm{rg} / 10.1111 / \mathrm{j} .1742-481 \mathrm{X} .2007 .00490 . \mathrm{x}$

[11] Vanwijck R, Kaba L, Boland S, et al. Immediate skin grafting of sub-acute and chronic wounds debrided by hydrosurgery. J Plast Reconstr Aesthet Surg. 2010; 63(3): 544-9. PMid: 19196559. http://dx.doi.org/10.1016/j.bjps.2008.11.097

[12] Venturi ML, Attinger CE, Mesbahi AN, et al. Mechanisms and clinical applications of the vacuum-assisted closure (VAC) Device: a review. Am J Clin Dermatol. 2005; 6(3): 185-94. PMid: 15943495. http://dx.doi.org/10.2165/00128071-200506030-00005

[13] Stetter C, Plaza T, von den Driesch P. Skin grafting of a chronic leg ulcer with combined Versajet-V.A.C. therapy. J Dtsch Dermatol Ges.
2006; 4(9): 739-42. PMid: 16928242. http://dx.doi.org/10. 1111/j.1610-0387.2006.06034.x

[14] Gurunluoglu R. Experiences with waterjet hydrosurgery system in wound debridement. World J Emerg Surg. 2007; 2: 10. PMid: 17475016. http://dx . doi.org/10.1186/1749-7922-2-10

[15] Rosales MA, Bruntz M, Armstrong DG. Gamma-irradiated human skin allograft: a potential treatment modality for lower extremity ulcers. Int Wound J. 2004; 1: 201-6. PMid: 16722878. http://dx.doi.org/10.1111/j.1742-4801.2004.00057.x

[16] Cancio LC, Horvath EE, Barillo DJ, et al. Burn support for Operation Iraqi Freedom and related operations, 2003 to 2004. J Burn Care Rehabil. 2005; 26(2): 151-61. PMid: 15756117. http: //dx.doi.org/10.1097/01.BCR.0000155540.31879.FB

[17] Canonico S, Campitiello F, Della Corte A, et al. The use of a dermal substitute and thin skin grafts in the cure of "complex" leg ulcers. Dermatol Surg. 2009; 35(2): 195-200. PMid: 19215255. http://dx.doi.org/10.1111/j.1524-4725.2008.34409.x

[18] Taniguchi T, Amoh Y, Tanabe K, et al. Treatment of intractable skin ulcers caused by vascular insufficiency with allogeneic cultured dermal substitute: a report of eight cases. J Artif Organs. 2012; 15(1): 77-82. PMid: 21861088. http://dx.doi.org/10.1007/s1004 7-011-0601-9

[19] Toyozawa S, Yamamoto Y, Kishioka A, et al. Effective treatment of intractable skin ulcers using allogeneic cultured dermal substitutes in patients with systemic lupus erythematosus. Eur J Dermatol. 2009; 19(6): 594-6. PMid: 19666399.

[20] Límová M, Mauro T. Treatment of leg ulcers with cultured epithelial autografts: clinical study and case reports. Ostomy Wound Manage. 1995; 41(8): 48-50, 52, 54-60. PMid: 7546120.

[21] Yamanaka K, Inaba T, Nomura E, et al. Basic fibroblast growth factor treatment for skin ulcerations in scleroderma. Cutis. 2005; 76(6): 373-6. PMid: 16438426.

[22] Giuggioli D, Colaci M, Manfredi A, et al. Platelet gel in the treatment of severe scleroderma skin ulcers. Rheumatol Int. 2012; 32(9): 292932. PMid: 21792645. http://dx.doi.org/10.1007/s00296-0 11-2038-0

[23] Giuggioli D, Sebastiani M, Cazzato M. Autologous skin grafting in the treatment of severe scleroderma cutaneous ulcers: a case report. Rheumatology. 2003; 42: 694-6. PMid: 12709550. http://dx.doi.org/10.1093/rheumatology/keg106 